\title{
Experimental investigation of Material Removal Rate and Tool wear in turning of hardened AISI52100 steel using Taguchi Technique
}

\author{
Vijaykumar H.K ${ }^{1}$, Ahamed Kabir ${ }^{2}$ and Ganesh Raj ${ }^{3}$ \\ ${ }^{1,2 \& 3}$ Department of Mechanical Engineering, Bearys Institute of Technology, Mangalore, Karnataka-574153, \\ India.
}

\begin{abstract}
The objective of this paper is to investigate experimentally the optimum process parameters (cutting speed, feed rate and depth of cut) resulting in an optimization of material removal rate (MRR) and tool wear while turning of hardened AISI 52100 steel under dry cutting conditions using Taguchi method. A L9 orthogonal array, signal-to-noise(S/N) ratio and analysis of variances (ANOVA) are applied with the help of Minitab.v.16.2.0 software to study performance characteristics of process parameters with consideration of Material Removal Rate (MRR) and Tool wear. The results obtained from the experiments are changed into signal-to-noise ratio(S/N) ratio and used to optimize the value of MRR and tool wear The ANOVA is performed to identify the importance of parameters. The conclusions arrived at are considerably discussed at the end.
\end{abstract}

Keywords: - ANOVA, Hardened, MRR, Tool wear, Taguchi technique

\section{INTRODUCTION}

In metal cutting industries the foremost drawback is not operating the machine tool to their optimum operating conditions and the operating conditions continue to be chosen solely on the basis of the handbook values or operator's experience. In metal cutting industries turning is the majorly used process for removing the material from the cylindrical work piece. In turning that to turning of hardened steels such as AISI52100 is a challenging process. Turning of hardened material is a process, in which materials in the hardened state (above 45HRC) are machined with single point cutting tools. This has become possible with the availability of the new cutting tool materials (cubic boron nitride and ceramics). The traditional method of machining the hardened materials includes rough turning, heat treatment followed by the grinding process. Turning of hardened material eliminates a series of operations required to produce the component and thereby reducing the cycle time and hence resulting in productivity improvement [1,2]. Turning of hardened material is an alternative to conventional grinding process; it is a flexible and economic process for hardened steels [3]. The advantages of tuning of hard materials are higher productivity, reduced set up times, surface finish closer to grinding and the ability to machine complex parts. Rigid machine tools with adequate power, very hard and tough tool materials with appropriate tool geometry, tool holders with high stiffness and appropriate cutting conditions are some of the prerequisites for hard turning [4].Material Removal Rate (MRR) is a vital factor to be considered in hard turning of steels since it is directly affects the machining time. It also had been reported that the resulting machining time reduction is as high as $60 \%$ in hard turning compared to grinding [5]. Tool wear specifically flank wear results in changes in tool geometry that affect cutting forces, cutting power, and surface finish. It is the main factor that determines the economics in metal cutting. A lower rate of flank wear means increased tool life, better surface finish, reduced tooling cost and lower cost of production.

The turning of hardened components are used in many applications such as gears, shafts, bearings, cams, forgings, dies and molds, which significantly reduce the manufacturing costs, lead times and improve overall product quality [6-9]. The hard turning is generally performed without a coolant using coated carbides, ceramics and cubic boron nitride cutting tools due to the required tool material hardness. The cutting tools required for hard turning are relatively expensive as compared to grinding operations and hence there is a need to investigate the flank wear to assure the economic justification for hard turning. The hard turning can provide a relatively high accuracy for hardened components but the problems occur with surface finish and flank wear. Numerous investigators have been conducted to determine the effect of parameters such as feed rate, tool nose radius, cutting speed and depth of cut on surface roughness in hard turning operation [10,11].Taguchi's Parameter design suggests an efficient approach for optimization of various parameters with regard to performance, quality and cost $[12,13]$. Taguchi recommends the use of $\mathrm{S} / \mathrm{N}$ ratio for the determination of the quality characteristics implemented in engineering design problems. The addition to $\mathrm{S} / \mathrm{N}$ ratio, a statistical analysis of variance (ANOVA) can be employed to indicate the impact of process parameters on MRR and surface roughness. In this paper Taguchi's DOE approach is used to analyze the effect of turning process 
parameters-cutting speed, feed and depth of cut while machining for hardened AISI52100 steel and to obtain an optimal setting of the parameters that results in optimizing MRR and flank wear.

\section{DETAILS OF EXPERIMENT}

\subsection{Workpiece Material, Cutting Tool and Machine}

The AISI 52100 steel work piece material is selected for the present work and the chemical composition of work piece material includes C- $0.93 \%, \mathrm{Cr}-1.43 \%, \mathrm{Mn}-0.43 \%, \mathrm{Si}-0.2 \%, \mathrm{P}-0.08 \%, \mathrm{~S}-0.0047 \%$ and balance Fe. The work pieces of diameter $18 \mathrm{~mm}$ and $100 \mathrm{~mm}$ length has been used for trials. For all the work pieces heat treatment was carried out. Initially before the heat treatment average hardness of the work piece was 22HRC. The heat treatment includes Hardening at $850^{\circ} \mathrm{C}$ for two hours and quenched with oil and also Tempering at $200^{\circ} \mathrm{C}$ for one hour. After heat treatment the average hardness value of $48 \mathrm{HRC}$ was obtained. The cutting tool insert used for machining AISI 52100 was carbide insert of ISO number: CCMT 32.52 MT TT8020 of Taegu Tec make under dry cutting conditions. The Cutting Tool holder used was of Specification SCLCR1212H09 D 4C of WIDIA make. The machine used for turning was all geared Head Precision lathe (Preci-Turnmaster -350) of OM JINA MACHINE TOOLS make. The instrument used for measuring weight of the specimen and flank wear was weighing balance and Tool maker's microscope respectively. Machining time is noted by stopwatch and measured final weight of all jobs. Material removal rate (MRR) is calculated by using relation MRR $=(\mathrm{Wi} .-\mathrm{Wf}) \div$ Machining Time, where $\mathrm{W}_{\mathrm{i}}$ is the initial weight of the workpiece and $\mathrm{W}_{\mathrm{f}}$ is the final weight of the work piece. The Taguchi method developed by Genuchi Taguchi is a statistical method used to improve the product quality in industries [14]. With the Taguchi method it is possible to significantly reduce the number of experiments. The Taguchi method is not only an experimental design technique, but also a beneficial technique for high quality system design [15].

\subsection{Taguchi Method}

The Taguchi technique includes the following steps:

- determine the control factors,

- determine the levels belonging to each control factor and select the appropriate orthogonal array,

- assign the control factors to the selected orthogonal matrix and conduct the experiments,

- analyze data and determine the optimal levels of control factors,

- perform the confirmation experiments and obtain the confidence interval,

- improve the quality characteristics.

The Taguchi method uses a loss function to determine the quality characteristics. Loss function values are also converted to a signal-to-noise $(\mathrm{S} / \mathrm{N})$ ratio $(\eta)$. In general, there are three different quality characteristics in $\mathrm{S} / \mathrm{N}$ ratio analysis, namely "Nominal is the best", "Larger is the better" and "Smaller is the better". For each level of process parameters, signal-to-noise ratio is calculated based on $\mathrm{S} / \mathrm{N}$ analysis.

\subsection{Selection of Control factors and orthogonal array}

In this study Cutting speed, Feed rate and Depth of cut (DOC) was selected as control factors and their levels were determined as shown in the Table 1.

Table 1Turning Parameters and their levels

\begin{tabular}{|c|c|c|c|}
\hline Factors & Level 1 & Level 2 & Level 3 \\
\hline Cutting Speed(rpm) & 450 & 710 & 1120 \\
\hline Feed rate(mm/rev) & 0.05 & 0.12 & 0.18 \\
\hline Depth of cut(mm) & 0.2 & 0.3 & 0.4 \\
\hline
\end{tabular}

The first step of the Taguchi method is to select an appropriate orthogonal array. The most appropriate orthogonal array (L9) was selected to determine the optimal turning parameters based on the total degree of freedom (DOF) and to analyze the effects of these parameters. The L9 orthogonal array has eight DOF and can handle three level design parameter. The L9 orthogonal array is as shown in the Table2.

Table 2 Orthogonal L9 array of Taguchi

\begin{tabular}{|c|c|c|c|}
\hline Experiment & P1 & P2 & P3 \\
\hline 1 & 1 & 1 & 1 \\
\hline 2 & 1 & 2 & 2 \\
\hline 3 & 1 & 3 & 3 \\
\hline 4 & 2 & 1 & 2 \\
\hline
\end{tabular}




\begin{tabular}{|l|l|l|l|}
\hline 5 & 2 & 2 & 3 \\
\hline 6 & 2 & 3 & 1 \\
\hline 7 & 3 & 1 & 3 \\
\hline 8 & 3 & 2 & 1 \\
\hline 9 & 3 & 3 & 2 \\
\hline
\end{tabular}

\section{ANALYSIS AND DISUSSION OF EXPERIMENTAL RESULTS}

Table 3 shows the experiment results for the flank wear and MRR and corresponding S/N ratios were obtained with the help of Minitab.v.16.2.0 software.

\subsection{Cause of Cutting speed, feed rate and Depth of cut on MRR}

From the response Table 4 and Fig. 1 it is clear that cutting speed is the most influencing factor followed by depth of cut and feed rate for MRR. The optimum for MRR is cutting speed of 1120rpm, feed rate of $0.12 \mathrm{~mm} / \mathrm{rev}$ and depth of cut of $0.4 \mathrm{~mm}$.

Table 3 Experimental results for the flank wear, MRR and corresponding S/N ratios

\begin{tabular}{|c|c|c|c|c|c|c|c|}
\hline Sl.No & $\begin{array}{c}\text { SPEED } \\
(\mathrm{rpm})\end{array}$ & $\begin{array}{c}\text { FEED } \\
(\mathrm{mm} / \mathrm{rev})\end{array}$ & $\begin{array}{c}\text { DOC } \\
(\mathrm{mm})\end{array}$ & $\begin{array}{c}\text { Flank } \\
\text { wear(mm) }\end{array}$ & $\begin{array}{c}\text { S/N Ratio } \\
\text { for flank wear }\end{array}$ & MRR(g/min) & $\begin{array}{c}\text { S/N Ratio } \\
\text { for MRR }\end{array}$ \\
\hline 1 & 450 & 0.05 & 0.2 & 0.11 & 19.17 & 0.008 & -41.89 \\
\hline 2 & 450 & 0.12 & 0.3 & 0.03 & 30.45 & 0.296 & -10.55 \\
\hline 3 & 450 & 0.18 & 0.4 & 0.64 & 3.87 & 0.086 & -21.23 \\
\hline 4 & 710 & 0.05 & 0.3 & 0.14 & 17.07 & 0.012 & -38.061 \\
\hline 5 & 710 & 0.12 & 0.4 & 1.23 & -1.79 & 0.113 & -18.87 \\
\hline 6 & 710 & 0.18 & 0.2 & 0.07 & 23.09 & 0.067 & -23.37 \\
\hline 7 & 1120 & 0.05 & 0.4 & 0.32 & 9.89 & 0.542 & -5.30 \\
\hline 8 & 1120 & 0.12 & 0.2 & 0.1 & 20.00 & 0.089 & -21.00 \\
\hline 9 & 1120 & 0.18 & 0.3 & 0.97 & 0.26 & 0.233 & -12.63 \\
\hline
\end{tabular}

Table 4 Response Table for Signal to Noise Ratios (Larger is better)

\begin{tabular}{|c|c|c|c|}
\hline Level 1 & Speed(rpm) & Feed(mm/rev) & DOC $(\mathrm{mm})$ \\
\hline 1 & -24.56 & -28.42 & -28.76 \\
\hline 2 & -26.77 & $-16.81^{*}$ & -20.42 \\
\hline 3 & $-12.98^{*}$ & -19.08 & $-15.41^{*}$ \\
\hline Delta & 13.79 & 11.61 & 13.62 \\
\hline Rank & 1 & 3 & 2 \\
\hline
\end{tabular}

* indicates optimum level

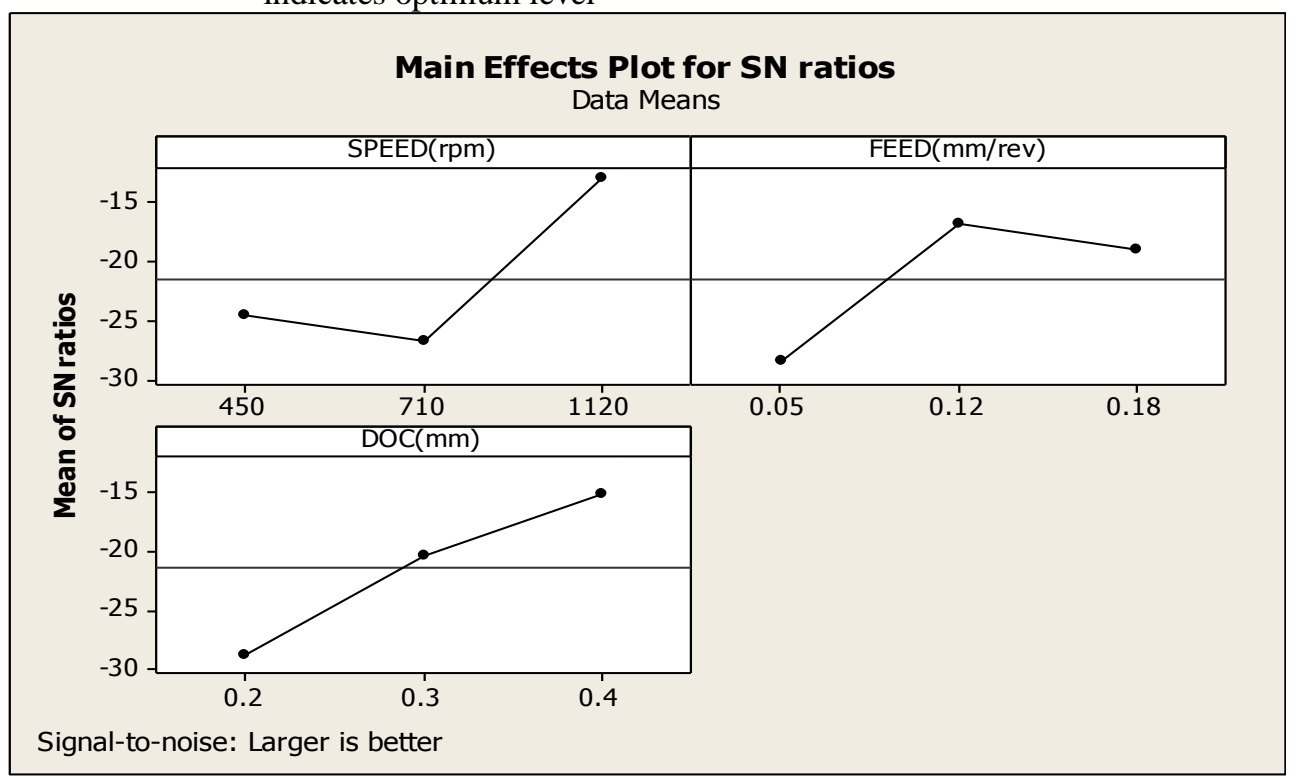

Figure 1 Main effects plots for MRR 


\subsection{Cause of Cutting speed, feed rate and Depth of cut on flank wear}

From the response Table 5 and Fig. 2 it is clear that depth of cut is the most influencing factor followed by cutting speed and feed for flank wear. The optimum conditions for flank wear are $450 \mathrm{rpm}$ feed rate of $0.12 \mathrm{~mm} / \mathrm{rev}$ and depth of cut of $0.2 \mathrm{~mm}$

Table 5 Response Table for Signal to Noise Ratios (Smaller is better)

\begin{tabular}{|c|c|c|c|}
\hline Level 1 & Speed(rpm) & Feed(mm/rev) & DOC(mm) \\
\hline 1 & $17.83^{*}$ & 15.38 & $20.75^{*}$ \\
\hline 2 & 12.79 & $16.22^{*}$ & 15.93 \\
\hline 3 & 10.05 & 9.08 & 3.99 \\
\hline Delta & 7.78 & 7.14 & 16.76 \\
\hline Rank & 2 & 3 & 1 \\
\hline
\end{tabular}

* indicates optimum level

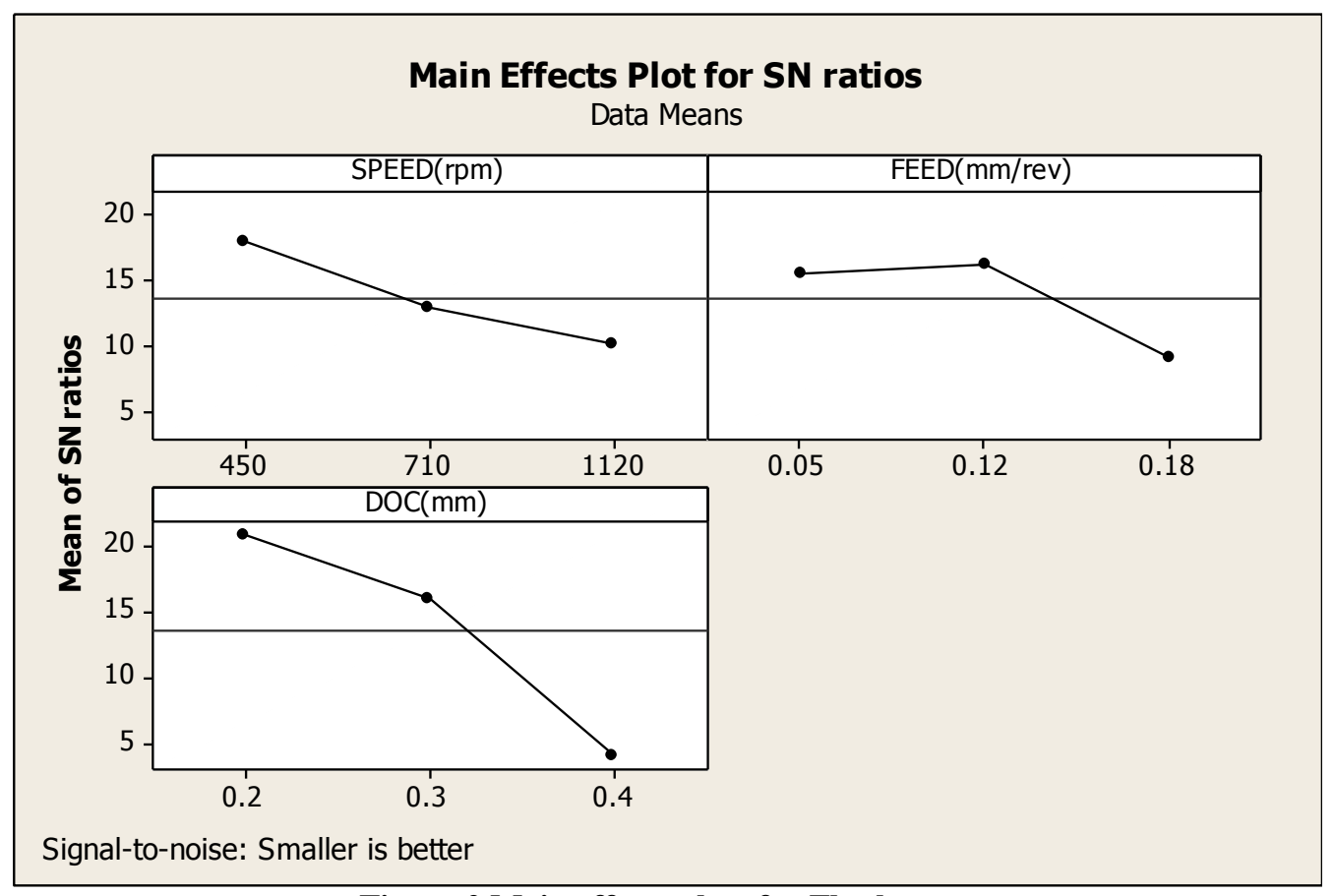

Figure 2 Main effects plots for Flank wear

\subsection{Analysis of variances (ANOVA)}

Taguchi method cannot judge and determine effect of individual parameters on entire process while percentage contribution of individual parameters can be well determined using ANOVA.Using Minitab.v.16.2.0 software ANOVA module can be employed to investigate effect of parameters. It is clear from the Table6 cutting speed (rpm) it is contributing of about $28.33 \%$, depth of cut $24.3 \%$ and feed rate $19.55 \%$ on Material Removal Rate (MRR).

Table 6 ANOVA for $\mathrm{S} / \mathrm{N}$ ratio for MRR

\begin{tabular}{|c|c|c|c|c|c|c|}
\hline Source & DOF & SS & MS & F & P & \% contribution \\
\hline Speed(rpm) & 2 & 329.2 & 164.6 & 1.02 & 0.495 & $28.33 \%$ \\
\hline Feed(mm/rev) & 2 & 227.2 & 113.6 & 0.70 & 0.587 & $19.55 \%$ \\
\hline DOC(mm) & 2 & 282.8 & 141.4 & 0.88 & 0.533 & $24.3 \%$ \\
\hline Error & 2 & 322.5 & 161.2 & - & - & $27.7 \%$ \\
\hline Total & 8 & 1161.7 & - & - & - & $100 \%$ \\
\hline
\end{tabular}


It is evident from Table 7 depth of cut is the most significant factor contributing of about $45.52 \%$, followed by cutting speed $9.5 \%$ and feed rate $9.3 \%$ on flank wear

Table 7 ANOVA for S/N ratio for flank wear

\begin{tabular}{|c|c|c|c|c|c|c|}
\hline Source & $\begin{array}{c}\text { DO } \\
\text { F }\end{array}$ & SS & MS & F & P & \% contribution \\
\hline Speed(rpm) & 2 & 93.5 & 46.7 & 0.27 & 0.789 & $9.54 \%$ \\
\hline Feed(mm/rev) & 2 & 91.4 & 45.7 & 0.26 & 0.793 & $9.32 \%$ \\
\hline DOC $(\mathrm{mm})$ & 2 & 446.9 & 223.5 & 1.28 & 0.439 & $45.52 \%$ \\
\hline Error & 2 & 349.9 & 174.9 & - & - & $35.62 \%$ \\
\hline Total & 8 & 981.7 & - & - & - & $100 \%$ \\
\hline
\end{tabular}

IV. VALIDATION OF EXPERIMENTS

After obtaining optimum conditions from Taguchi method of both MRR and flank wear the prediction was made for MRR and flank wear. The predicted value of MRR for optimum conditions of cutting speed $1120 \mathrm{rpm}$ feed rate $0.12 \mathrm{~mm} / \mathrm{rev}$ and depth of cut $0.4 \mathrm{~mm}$ is $0.782 \mathrm{~g} / \mathrm{min}$ and when the actual experiment was done using these optimum conditions the MRR obtained is $0.807 \mathrm{~g} / \mathrm{min}$ therefore the error obtained is $2.5 \%$ as shown in Table8.

Table 8 Confirmation test for MRR

\begin{tabular}{|c|c|c|c|c|}
\hline Optimum Values & S/N ratio obtained & Predicted MRR(g/min) & Actual MRR(g/min) obtained & Error\% \\
\hline Speed: $1120 \mathrm{rpm}$ & -2.05574 & 0.782 & 0.807 & $2.5 \%$ \\
Feed:0.12mm/rev & & & & \\
DOC: $0.4 \mathrm{~mm}$ & & & & \\
\hline
\end{tabular}

The predicted value of flank wear for optimum conditions of cutting speed 450rpm feed rate $0.12 \mathrm{~mm} / \mathrm{rev}$ and depth of cut $0.2 \mathrm{~mm}$ is $0.0412 \mathrm{~mm}$ and when the actual experiment was done using these optimum conditions the surface roughness obtained is $0.04 \mathrm{~mm}$ therefore the error obtained is $1.2 \%$ as shown in Table 9.From these confirmation tests, good agreement between the predicted machining performance and the actual performance were observed.

Table 9 Confirmation test for flank wear

\begin{tabular}{|c|c|c|c|c|}
\hline Optimum Values & $\begin{array}{c}\text { S/N ratio } \\
\text { obtained }\end{array}$ & $\begin{array}{c}\text { Predicted flank } \\
\text { wear(mm) }\end{array}$ & $\begin{array}{c}\text { Actual flank } \\
\text { wear(mm) obtained }\end{array}$ & Error\% \\
\hline $\begin{array}{c}\text { Speed:450rpm } \\
\text { Feed:0.12mm/rev }\end{array}$ & 27.69 & 0.0412 & 0.04 & $1.2 \%$ \\
DOC:0.2mm & & & & \\
\hline
\end{tabular}

\section{CONCLUSION}

- The optimum conditions obtained from Taguchi method for optimizing Material Removal Rate (MRR) during turning of hardened AISI52100 steel under dry condition are cutting speed of 1120rpm Feed rate of $0.12 \mathrm{~mm} / \mathrm{rev}$ and depth of cut of $0.4 \mathrm{~mm}$.

- From response table for S/N ratio of MRR it is clear that cutting speed is the most significant factor influencing MRR followed by Depth of cut and Feed rate is the least significant factor.

- Analysis of Variances (ANOVA) for S/N ratio for MRR clearly indicates that the cutting speed is majorly contributing of about $28.33 \%$ in obtaining optimal MRR followed by depth of cut $24.3 \%$ and feed rate $19.55 \%$.

- Optimum conditions for optimizing flank wear are cutting speed of 450rpm Feed rate of $0.12 \mathrm{~mm} / \mathrm{rev}$ and depth of cut of $0.2 \mathrm{~mm}$

- From response table for $\mathrm{S} / \mathrm{N}$ ratio of surface roughness it is clear that depth of cut is the most significant factor influencing flank wear followed by cutting speed and feed rate which is the least significant factor.

- Analysis of Variances (ANOVA) for S/N ratio for surface roughness clearly indicates that the depth of cut is majorly contributing of about $45.52 \%$ in obtaining optimal flank wear followed by cutting speed $9.54 \%$ and feed rate $9.32 \%$. 


\section{REFERNCES}

[1] Grzesik, W., Wanat, T, Surface finish generated in hard turning of quenched alloy steel parts using conventional and wiper ceramic inserts, International Journal of Machine Tools and Manufacture, vol. 46, 2006,1988-1995.

[2] Siler, H.R., Vila, C., Rodríguez, C.A., Abellán, J.V, Study of face milling of hardened AISI d3 steel with a special design of carbide tools, Int J. Adv. Manuf. Technol., vol. 40,2009, 12-25.

[3] Tonshoff HK,Wobker HG,Brandt D, Tool wear and surface integrity in hard turning, ProductionEngineering, 3(1), 1996,19-24.

[4] Ali Riza Motorcu, The Optimization of Machining Parameters Using the Taguchi Method for Surface Roughness of AISI 8660 Hardened Alloy Steel,Journal of Mechanical Engineering, 2010, 391-401

[5] Tonshoff HK, Wobker HG,Brandt D, Hard-turning-Influence on the workpiece properties, Trans NAMRI/SME, 1995,215-220.

[6] Zou JM, Anderson M, Stahl JE, Identification of cutting errors in precision hard turning process. J Mater Process Tech 2004; 153-154:746-50.

[7] Rech J, Moisan A, Surface Integrity in finish hard turning of case hardened steels. Int Journal Machine Tool Manufacturing 2003; 43:543-50.

[8] Destefani J, Technology key to mold making success, International Journanal of Manufacturing Engg, 2004; 133(4):59 64.

[9] Elbestawi MA, Chen L, Becze CE, EI-Wardany TI, High-speed milling of dies and molds in their hardened state. Ann CIRP, 1997; 46(1):57-62.

[10] X.L. Liu, D.H. Wen, Z.J. Li, Xiao, .G. Yan, Experimental study on hard turning of hardened GCr15 steel with PCBN tool, Journal of Materials Processing Technology, 129 ,2002, 217-221.

[11] S. Thamizhmanii, S. Saparudin, S. Hasan, Analyses of surface roughness by turning process using Taguchi method, JAAME, vol 20, 2007,503-506.

[12] Ross P J, Taguchi Techniques for Quality Engineering (McGrawHill NewYork, 1995).

[13] Taguchi G, Introduction to Quality Engineering (Asian Productivity, Organization Tokyo, 1990).

[14] Pınar, A.M., Güllü, A, Optimization of numerical controlled hydraulic driven positioning system via Taguchi method. Journal of Faculty Engineering Architectural Gazi University, vol. 25, no.1, 2010, 93 100.

[15] Savaşkan, M., Taptık, Y., Ürgen, M,Performance optimization of drill bits using design of experiments. Journal of ITU, vol. 3, no. 6, 2004, 117-128. 